\section{Everything you wanted to know about}

\section{Leslie Crombie}

The Natural Coumarins: Occurrence, Chemistry and Biochemistry. By Robert D.H. Murray, Jesus Mendez and Stewart A. Brown. Pp.702. ISBN 0-471-28057-7. (Wiley: 1982.) $£ 70, \$ 160$.

MORE than 800 natural coumarins are known today, many from higher plants, but a number are important compounds from microbial sources and include antibiotics as well as the more notorious group of aflatoxins. With the appearance of this large and well-printed volume there can be few groups of natural products which have so modern and extensive a documentation; indeed if there were more volumes of this type natural products study would become much more accessible, and some order brought to a massive and rather sprawling area of science.

The volume should attract more than one type of reader and in some ways it is two books in one. Chapters 1-8 will be of special interest to natural products organic chemists interested in the themes of structure, synthesis and biosynthesis. These chapters are particularly impressive for their depth of coverage, bringing together much scattered information. The style of writing is pleasant, and older information is integrated with newer material in a way which gives the reader confidence in the judgement and scholarship of the authors. There is much here in the chemistry, synthesis and use of spectroscopic and other techniques to attract the noncoumarin specialist.

Chapters 9-13, the second part of the text, have biochemically orientated themes which tend to concentrate on certain biologically active structures such as the aflatoxins, dicoumarol, novobiocin and the furanocoumarins. All these compounds have interesting biochemical interactions which lend themselves well to an essay-type of treatment. Some are of more recent discovery, but knowledge of the effects of the furanocoumarins (e.g. from rue) goes way back in time, and photosensitization reactions in skin by their linear members are now well studied. An indication of what our ancestors thought about the biological activity of certain plant furanocoumarins is given in the concise lines,

Rue maketh chast and eke preserveth sight, Unfuseth wit, and Fleas doth put to flight.

These claims, however, are perhaps somewhat excessive.

Despite a careful exposition of the different numbering systems for coumarins given early in the book, it is unsettling that two systems are employed in different parts of the text for furanocoumarins, one intended for chemists, one for biochemists and biologists. There are instances of interesting but unreferenced items, such as chlorflavonin (p.101), but few errors jar the reader's pathway. Nonetheless the strong recommendation, in heavy black type, of a total ban on benzene for extraction and chromatography on the grounds of toxicity hazards, does seem a little excessive. If professional chemists cannot handle toxic materials by safe working, who then will?

Impressive features of this book are the indexes and tables which must have involved a remarkable amount of work. These cover 379 pages of the 702-page book. Natural coumarins are tabulated according to chemical type along with trivial name, empirical formula, melting point, rotation and references. There are then separate indexes of melting point, molecular weight, trivial names, botanical occurrence, and families and genera, together with a general index and 3,383 references - we shall henceforth have little excuse for not being able to find specific pieces of information on natural coumarins. This is a massive work, with strong elements of original treatment, which will become a valued and wellknown book among scientists in the natural product area.

Leslie Crombie is Sir Jesse Boot Professor of Organic Chemistry at the University of Nottingham.

\section{Reprise of calcium and secretion}

\section{O. H. Petersen}

Calcium and Cellular Secretion. By Ronald P. Rubin. Pp.276. ISBN 0-306-40978-X. (Plenum: 1982.) \$35, £22.05.

THE importance of calcium in the control of secretion has not been in dispute for many years. However, the realization of the key role played by calmodulin, the demonstrations of the internal calcium control of membrane conductance, the characterization of calcium channels and the availability of much improved methods for measuring the internal free calcium concentration, together with many other important findings made in the past ten years, is certainly justification for a new book on the subject. This monograph is a much improved version of Calcium and the Secretory Process by the same author, which appeared in 1974 (for review see Nature 255, 265; 1975).

The present book is only slightly longer than its predecessor, but contains much new material reflecting the rapid growth of this research field. There are four main chapters. The first deals with a mixture of general problems such as analytical techniques, subcellular calcium distribution and its redistribution during stimulation. There is a wealth of useful information including a critical assessment of calcium antagonists. Unfortunately the sections on calcium channels and the effects of internal calcium on other ion channels are already out of date, since there is no mention of single-channel current recordings with the Neher/Sakmann patch clamp technique. Dr Rubin can hardly be blamed for this, since the results of the application of this powerful technique to secretory cells have only recently been appearing in print. More worrying is the author's tendency to quote reviews rather than original papers. This can have unfortunate consequences as seen in the discussion of the calcium-evoked potassium release, where no reference to Gardos is found although this phenomenon is generally associated with his name.

The second chapter is a survey of calcium actions covering all the main secretory cell types. The historical development of the stimulus-secretion coupling concept is traced by considering first the cholinergic nerves and then the adrenal medulla and the neurohypophysis, but perhaps because these three systems are discussed mainly in a historical context one looks in vain for even a brief description of the BakerKnight experiments with permeabilized adrenal medulla cells (Nature 276, $620-622 ; 1978)$. It is sad that an otherwise fine chapter, which is on the whole up to date, should be marred by the failure to discuss one of the most direct approaches to the question of intracellular control of secretion.

Chapter 3 is a brief consideration of possible mechanisms by which calcium acts to control secretion. There is rightly emphasis on calcium-binding proteins and in particular calmodulin, but it is clear that many important pieces of the puzzle are still missing. Finally, the author deals with the interactions of calcium with other putative intracellular mediators, in particular cyclic AMP and cyclic GMP. The picture is far from clear, but this again is not Dr Rubin's fault. These are muddy waters and much remains for research workers to discover and probably also "undiscover".

Dr Rubin's compact monograph will be useful to the many students of this exciting research field. It is not yet the ideal book on the topic, but considering the difficulties in compressing the vast amount of available material into what has become a very readable book, we must be grateful for this effort.

O. H. Petersen is George Holt Professor of Physiology at the University of Liverpool, and author of The Electrophysiology of Gland Cells (Academic, 1980). 